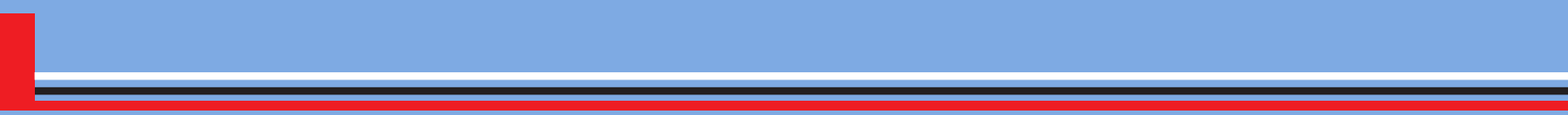




\section{Movimiento urbano ciclista. Imaginarios colectivos convertidos en expresiones materiales ${ }^{1}$}

Escudero, M. C., \& Uribe, C. (2016). Movimiento urbano ciclista, Imaginarios colectivos convertidos en expresiones materiales. Designia, 4(1), 99-115.

Urban cyclist movement. Collective imaginary Turned into material expressions.

\section{Resumen:}

\section{Palabras clave: \\ bicicleta, prácticas, ciudad, cultura, sociedad. Key words:}

bicycle, practices, city, culture, society

Recibido: 28-mar- 2016 Aceptado: 4-ago- 2016

\footnotetext{
${ }^{1}$ Proyecto de investigación cualitativa para grado de Diseñador Industrial. Escuela de Arquitectura y Diseño, Universidad Pontificia Bolivariana sede Medellín. GED (Grupo de Estudios en Diseño) Área de Cultura Material.
}

\section{*Diseñadora Industrial, Universidad Pontificia Bolivariana, Medellín. maria.escudero@upb.edu.co}

Diseñadora Industrial, Universidad Pontificia Bolivariana, Medellín. catibez@hotmail.com
El presente artículo de investigación científica y tecnológica es el resultado de una investigación con enfoque cualitativo realizada en la ciudad de Medellín. El objetivo principal fue reconocer los significados que ha adquirido la bicicleta como medio de manifestación ante temas sociales, políticos y culturales entre los grupos conformados alrededor de ella. Cuatro propósitos con carácter académico se resaltan en este trabajo: primero, identificar esos colectivos y las actividades surgidas a partir del uso de la bicicleta; segundo, establecer una relación entre esta, las materialidades y las partes adicionales funcionales y estéticas; tercero, evidenciar el sentido dado a las prácticas y materialidades identificadas; cuarto, analizar el impacto de los grupos, sus manifestaciones pacíficas y de reclamación social en la configuración de la ciudad, su infraestructura y movilidad. La relevancia de tales dinámicas y significados se abordó en compañía de líderes de los ciclistas y otros agentes miembros de entidades públicas relacionadas con el tema, haciendo énfasis en resultados que permitan crear nuevos conceptos para el diseño en relación con la cultura material.

\section{Abstract}

This paper is derived from a qualitativeapproach research conducted in the city of Medellin whose objective was to recognize the meanings bicycle has acquired among the groups formed around it, as a means of protest against social, political and cultural issues. Four academic purposes are highlighted: first, identifying such collectives along to the activities arising from the use of bicycle; second, finding links between it, the materiality and the functional-aesthetic gadgets added to it; third, finding out the sense given to both the materiality and the practices identified; and finally, reviewing the groups' peaceful and social-claim manifestations as well as their impact on the city's configuration, infrastructure and mobility. Cyclists' leaders and members of public departments were invited to assess these dynamics, emphasizing in creating new concepts for the design in relation with material culture. 
En Medellín, como en muchas otras ciudades de Latinoamérica, algunos ciudadanos han buscado reconfigurar el pensamiento colectivo con el fin de hacerla incluyente y que gire en torno a las alternativas de transporte limpio, cuidado del medio ambiente y movilidad equitativa dentro del espacio público. Desde hace cuatro años este pensamiento viene generando cambios sociales y culturales que de alguna manera influyen en la planeación de la infraestructura urbana. Parte importante de este cambio es el movimiento ciclista, fortalecido en años recientes.

Con base en lo anterior, surgió la pregunta respecto a los significados que la bicicleta ha adquirido como medio de manifestación de los colectivos culturales ante problemas sociales y políticos en la capital antioqueña. Se dio inicio así a una investigación de orden científico y tecnológico de enfoque cualitativo con el fin de responder el interrogante, al tratarse de una temática no abordada desde la cultura material. El objetivo general fue reconocer esos significados dentro de los grupos conformados alrededor de la bicicleta en Medellín, en tanto como objetivos específicos para dar respuesta a ese principal se formularon los siguientes: 
Engalle, es un término comúnmente utilizado para denotar la forma de personalizar y caracterizar objetos por medio del uso de otros objetos, haciéndolo particular o diferente de objetos parecidos.
- Identificar los colectivos y las actividades que han surgido a partir del uso de la bicicleta como medio de manifestación pacífica y símbolo del movimiento ciclista. - Establecer, con los distintos grupos y sus actividades, una relación entre las materialidades, la bicicleta y las partes adicionales de engalle ${ }^{2}$ funcional y estético, - Evidenciar el sentido dado a las prácticas y las materialidades identificadas.

- Analizar el impacto de los colectivos, sus manifestaciones pacíficas y de reclamación social en la configuración de la ciudad, su infraestructura y movilidad.

Como primera medida se indagaron temáticas y conceptos. Por ejemplo, los planes, cambios y propuestas del Estado que se dan por las iniciativas de los ciudadanos, como también las solicitudes realizadas por estos para obtener mejores condiciones de movilidad y transporte limpio. Todo esto nos hizo conscientes del reto que representa gestionar la planeación de la ciudad hacia el desarrollo común, en una conjugación de factores económicos, sociales y ambientales para buscar la equidad en tales ámbitos. Diferentes conceptos nos ayudaron a comprender el panorama general del movimiento urbano abanderado por la bicicleta, concebida como un objeto cuya materialidad y connotaciones simbólicas encierran una red de relaciones, expresiones individuales y colectivas, reclamaciones políticas y apropiaciones del espacio. Su uso como medio de transporte habitual es incentivado en aras de cambiar determinadas costumbres de quienes la adoptan.

La transformación de las bicicletas se ha convertido en una actividad comercial que desemboca en un movimiento cultural centrado en las dinámicas de la cultura material, el cual nació y gira en torno a un objeto con diversos significados a partir de su uso. Sus diferentes manifestaciones despiertan nuestro interés como un tema amplio en que además de las materialidades y los usos, intervienen objetivos de mejoramiento en el medio ambiente, las personas, los espacios y en prácticas reveladoras de un cambio en los comportamientos colectivos. 


\section{FUNDAMENTACIÓN CONCEPTUAL}

Para abordar la investigación fue necesario comprender los siguientes conceptos, definidos desde distintas disciplinas, para luego construir una definición propia que respondiera a los objetivos planteados.

Según Diéguez y Guardiola (1998) y Morin (1960) los colectivos culturales están conformados por individuos con características e ideales similares, quienes buscan a través de su relación trabajar por propósitos comunes. Esas semejanzas los llevan a identificarse dentro de un espacio habitado por otros colectivos. A través de la búsqueda documental encontramos conexiones entre este concepto y los de comunidad y mancomunidad, para crear así una imagen de los grupos formados dentro de la ciudad con metas puntuales.

Comunidad se interpreta como una forma de relación social definida por la reunión de personas con un fin, quienes participan de un sistema de intereses y actividades que incluye sus orientaciones particulares y vínculos comunes ligados a la inclusión de la sociedad. Busca agrupar dentro de una sola denominación a quienes apuntan a pertenecer activamente a un grupo con propósitos específicos, lo cual implica el cumplimiento de derechos y deberes que afectan directamente los objetivos

El movimiento ciclista en Medellín tiene una trascendencia en el tiempo y desde que la bicicleta empezó a ser un objeto importante de manifestación y transporte, su uso, el pensamiento de los individuos y la mutación física de la ciudad han mostrado una ruptura, un cambio de paradigma y un viraje en la visión colectiva frente al espacio público, quienes lo habitan y las materialidades que marcan esta relación. compartidos. La mancomunidad, por su parte, se centra en la unión de poblaciones que se integran con el fin de implementar y hacer cumplir sus derechos. Junto a este concepto aparece siempre la creación de democracias participativas que buscan el crecimiento del ciudadano como sujeto.

Después de definir los colectivos culturales, con sus intereses políticos y sociales, notamos que estos adquieren una voz a través de la acción política, definida por Ema (2007) -retomando a Ranciére - a partir del acontecimiento político como una gestión comunitaria destinada a posibilitar prácticas y pensamientos subjetivos, para generar además espacios físicos habitables. Asimismo, la producción de otras formas de vida basadas en patrones sostenibles o dirigidos al cambio de ciertas prácticas comunitarias representa un elemento clave de este concepto. Por medio de 
la acción política y sus acontecimientos los colectivos son escuchados y pueden modificar sus condiciones a través del discurso, la acción pacífica y la construcción de espacios que se van transformando en la ciudad.

A partir de estas acciones políticas y manifestaciones culturales se logran transformaciones y apropiaciones del espacio público, definido por la Constitución Política de Colombia (2015) como bienes de uso público, parques naturales, tierras comunales de grupos étnicos y de resguardo, patrimonio arqueológico de la Nación y demás bienes determinados por la ley como inalienables, imprescriptibles e inembargables. Por su parte, para García (s.f.) y Recendiz (2013), se trata del espacio de identificación simbólica de distintos grupos sociales, desde su configuración física y su capacidad de apertura y adaptación.
El espacio público se concibe aquí desde la arquitectura, la infraestructura y los recursos económicos públicos, con la intención de ser planeado sin tergiversaciones o agresiones y para ser vivido a través de actividades públicas en las cuales participen todos los habitantes, con sus intereses individuales y colectivos. Dicha participación no ha de quedarse solo en la asistencia y el acto de presencia, sino trascender la apropiación de ese espacio y sus elementos individuales, para convertirlo en lugar de identidad y cultura urbana. En estas acciones, ciertos elementos entran a hacer parte de la identidad de los grupos que se unen con fines políticos, imaginarios espaciales y materiales. Se trata de objetos que median en la relación entre las personas y los espacios, adquieren rasgos significativos en su construcción y dan pie al engalle de otros objetos.

Según Rojas y Guerrero (1999), Sanín (2009) y Carvajalino (s.f.) el engalle es, en este caso, la base de transformación de la cultura, la apropiación y personalización que busca la identificación, el reconocimiento y la diferenciación dentro de los colectivos culturales. Tal apropiación, individual o colectiva, se da por medio de un uso expresado en el cambio de aspectos físicos como la forma y el material, las partes y la estructura. De esta manera, a través de objetos con los que hay una relación en la cotidianidad, se muestra una identidad puramente individual o derivada de la grupal, se materializan gustos y pensamientos, y los propios objetos se cargan con sentidos y significados particulares mientras siguen reflejando patrones de gustos colectivos, presentes en gran parte la sociedad.

El engalle ocupó un lugar primordial en la investigación al ser una acción de los colectivos que relaciona el sujeto con el contexto por medio del objeto y la acción. Además, representa una forma de apoyo a la acción política pacífica orientada a la consecución de objetivos comunitarios y al mostrarse en los espacios urbanos, potencia la adopción de estos como escenarios de socialización y participación. 
Siguiendo a Díaz y Ortiz (2006)

y Moranta y Urrútia (2005), en la apropiación del espacio se valora su uso por parte de los colectivos, lo cual sugiere que la mezcla socioespacial se convierte en fragmentación socioespacial. Esto es esencial en el estudio de la cotidianidad de los pobladores de las ciudades. Se da a partir de los usos del espacio público, en este caso un escenario urbano que en cierta medida responde a las necesidades de los habitantes y donde a pesar de sus falencias infraestructurales $y$ de planeación, los colectivos son impulsados a expresarse por medio de actividades y materialidades, reflejo de sus deseos de ser escuchados.

El desarrollo humano y el de un territorio están, a su vez, directamente ligados: si el índice de uno aumenta lo hace también el otro. Por lo tanto, son temas de interés social, determinantes para el incremento de la calidad de vida y la formación cultural de una sociedad. Desde la perspectiva del desarrollo, el espacio adquiere un carácter político y oficial, basado en la planeación oficial.
Los cambios estructurales oficiales en el espacio público son consentidos desde la planeación urbana, definida por Echebarría y Aguado (2003), González (1992) y Peralta (2010), como la función de la administración pública encargada de detectar las necesidades colectivas y particulares, conjuntamente con las actividades realizadas dentro de tal espacio para generar respuestas basadas en estrategias, infraestructura y ordenamiento territorial. Se trata de una compleja tarea que requiere de una visión integral de los fenómenos causantes del crecimiento urbano y no solo debe relacionarse con la distribución de los usos del suelo, sino también con la ubicación eficiente de los recursos, con los problemas de la comunicación y el movimiento entre la vivienda, el trabajo y la recreación.

El tema se toca en ocasiones de manera superficial, pues resulta delicado hablar de intereses sociales cuando con regularidad se demanda la forma como las entidades gubernamentales, al administrar los recursos, evitan que estos sean realmente invertidos en obras públicas de beneficio colectivo y terminan en el trasfondo de proyectos nunca ejecutados o en salarios de los administradores a cargo de ellos.

La planeación urbana corresponde al Estado, pero son los ciudadanos quienes realmente la conciben a través de sus actividades diarias, en las que marcan pautas para mejoras y renovaciones. En este sentido, también son un aporte importante las manifestaciones pacíficas y las apropiaciones extraoficiales del espacio, cuando no lo dañan ni lo violentan. 


\section{METODOLOGÍA}

Una vez realizada esta comprensión conceptual, pasamos a la construcción de las herramientas para la obtención de información en el trabajo de campo que nos permitiera contrastar los conceptos examinados con la realidad. Por tratarse de una investigación cualitativa nos concentramos en una situación social en un espacio y tiempo determinados (Castro \& Rodríguez, 2005). Así, apuntamos a encontrar patrones de pensamiento y de acción dentro de los colectivos urbanos conformados en Medellín en torno a la bicicleta.

Los conceptos de la estructura teórica derivaron en variables de análisis que ayudaron a definir y diseñar los instrumentos (tres tipos de entrevista y una ficha de análisis fotográfico). También especificamos la muestra para el trabajo de campo, enfocándonos en fuentes primarias que nos brindaran información relevante.

Dicho trabajo se dividió en dos fases. La primera fue una prueba piloto en que comprobamos la pertinencia de los instrumentos y nos permitió incorporar los ajustes necesarios. Hecho esto, procedimos a entrevistar a expertos, integrantes de los

La planeación urbana está entonces directamente ligada a las apropiaciones hechas por los colectivos culturales sobre el espacio público, en nuestro caso a través de la bicicleta como canal y el engalle como mensaje, los cuales constituyen un medio simbólico objetual para efectos de la acción política y las manifestaciones culturales. Estas terminan por influir en la configuración y transformación del espacio a través de la búsqueda de determinados ideales. colectivos y ciudadanos en general. La muestra estuvo constituida por un experto en organización, líder del colectivo Siclas, un participante de este y un usuario de la bicicleta como medio de transporte habitual. Para la fase final entrevistamos a un arquitecto experto en urbanismo y movilidad, a tres líderes de diferentes grupos, un periodista, un sociólogo y al dueño de uno de los locales de personalización más reconocidos en la ciudad.

Asistimos a las Sicladas, actividad convertida en forma de expresión y apropiación espacio-temporal de las calles, en la cual los colectivos se hacen visibles y expresan sus opiniones respecto a temas ambientales, culturales y urbanos. En 2015 estuvimos tanto en el preforo Mundial de La Bicicleta, realizado en la Universidad Pontificia Bolivariana de Medellín y en el que se reunieron miembros de los grupos, representantes de la Secretaría de Movilidad y otros entes del Estado, como en el 


\section{RESULTADOS Y DISCUSIÓN}

\section{Respecto a los colectivos culturales}

Se identificaron siete grupos conformados alrededor de la bicicleta, los cuales la han asumido como solución frente a asuntos de movilidad, contaminación y cultura. Además, la defienden de los críticos y le asignan bondades de "máquina perfecta".

Cada colectivo se mueve de acuerdo con sus objetivos. Algunos vitalizan la ciudad al transitar por calles principales y barrios; cantan, pitan, gritan e invitan a los residentes a unirse y a aprender de forma recreativa a movilizarse en este medio, de modo tal que se convierta no solo en un hobby sino en un hábito.

Algunos líderes de los grupos participan en procesos de toma de decisiones. No obstante, esto ha sido posible por el manejo de influencias, situación que ha sido vista por otros líderes y participantes como excluyente pues las peticiones y los cam-

posterior Foro Mundial cuyo escenario bios logrados solo benefician a personas de alto poder adquisitivo residentes en la zona plana, pero dejan por fuera de los planes de desarrollo vial o de infraestructura a quienes viven en las laderas, en medio de una difícil topografía.

encuentro, líderes en movilidad sostenible de diferentes países del mundo expusieron casos de urbes donde se han acogido estrategias de movilidad y cultura, por ende, son un modelo positivo frente a los cambios que se viven en Medellín.

Finalmente, categorizamos y analizamos la información mediante matrices que relacionaron las actividades, los objetivos de los colectivos, las materialidades que emplean para comunicarse y su impacto en la transformación urbana.

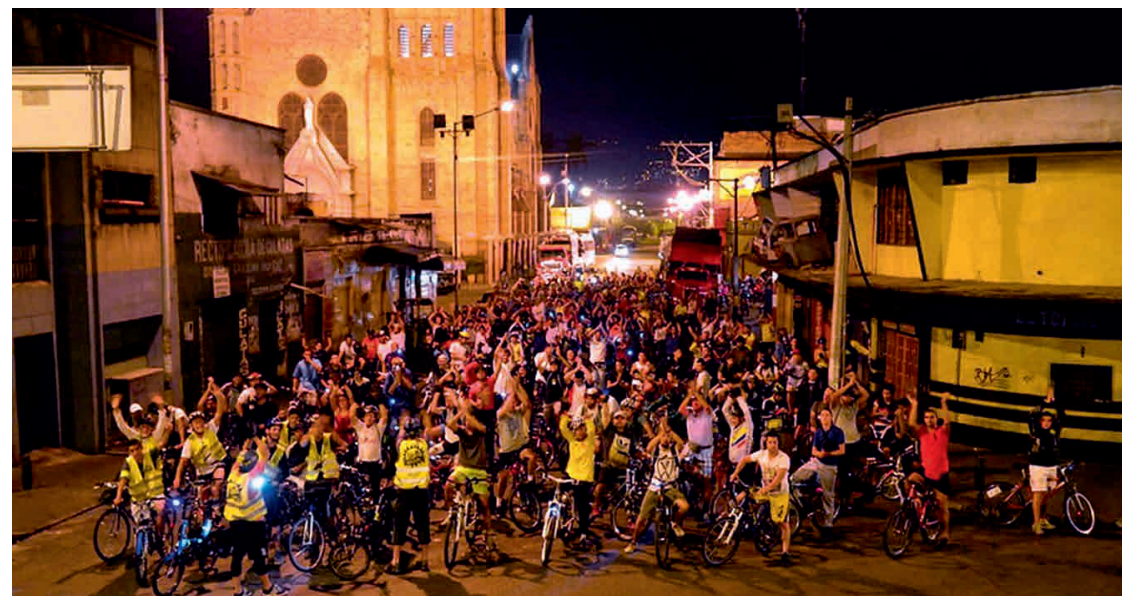

Figura 1. Miembros del colectivo Siclas transitando por los barrios en una de las Sicladas de los miércoles. Mayo de 2015 Fuente: https://www.flickr.com/photos/siclas/ 
Respecto a la acción política

Algunos testimonios encuentran en estos movimientos una actividad elitista en que solo tienen participación con capacidad decisiva personas influyentes con intereses políticos, interesadas en generar tensiones y llamar la atención para atraer adhesión a sus propios grupos. Esto también es llamado poder de convocatoria. El asunto ha generado incluso prejuicios hacia las agrupaciones y los motivos de su conformación. Ciertamente, estas poseen objetivos y usan la bicicleta de manera simbólica para conectarse con la ciudad, pero no siempre hay claridad de su parte frente a la ciudadanía al presentar sus propósitos de cambiar paradigmas socioculturales. En consecuencia, se les percibe como motivados por intereses políticos y en ocasiones económicos. Si bien sus procesos sociales no son por completo incluyentes o excluyentes, sus líderes tienen claro que solo a aquellos con ideologías claras es posible otorgar una voz determinante, aunque todos los participantes son acogidos y en las actividades periódicas pueden exponer ideas.
Es notable que las respuestas del Estado ante las peticiones de los colectivos no siempre son oportunas o acertadas. Esto se manifiesta en inconsistencias que van desde el sacrificio de la infraestructura peatonal para asegurar la del ciclista hasta la ausencia de una normativa destinada a garantizar a los ciudadanos una movilidad adecuada sin interferir en la circulación del otro.

Cuando el Estado contesta estas peticiones puede suceder que lo hace por medio de un plan pedagógico o de mejoras de infraestructura, o desde el Plan de Ordenamiento Territorial, o bien con la creación de una organización oficial como la Mesa Metropolitana de Movilidad. De uno u otro modo se generan cambios, pues todas estas acciones terminan influyendo en la configuración del espacio público.

Carlos Enrique Quiceno Quiceno es un personaje particular que se ha convertido en un ícono del colectivo. Para cada recorrido cambia la frase de su bandera y siempre invita a los ciudadanos a adquirir conciencia, a respetar a los demás ciudadanos y a volverse ciclistas por convicción (Figura 2).

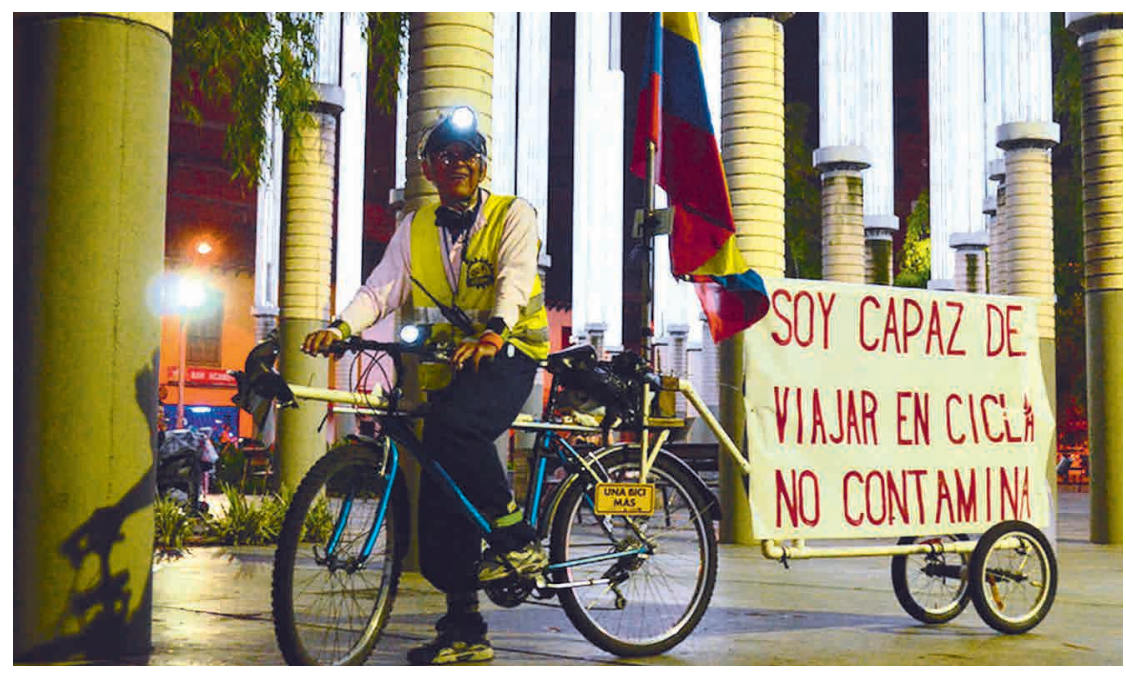

Figura 2. Miembro del colectivo Siclas llevando su mensaje junto a la bandera nacional en un recorrido por lugares representativos de la ciudad. Mayo de 2015 Fuente: https://www. Flickr.com/photos/siclas/ 


\section{Respecto al espacio público}

Aunque no lo planifiquen, los colectivos pueden influir en la concepción del espacio público a través de sus prácticas y hábitos, de modo tal que lo configuren, transformen y apropien sin tergiversarlo o agredirlo, simplemente usándolo. Esto lo lleva a ser un "lugar de la identidad" con el que ciertos individuos se identifican, donde se crean conexiones y se guarda la historia de sus anteriores ocupantes, la huella dejada por los transeúntes. Es común ver murales, grafitis, pancartas y pasacalles en nuestra ciudad, expresiones que invitan a apropiarse de los espacios, a generar cultura ciudadana y vial. Cada colectivo tiene una forma diferente de intervenir el espacio, de transformarlo $y$ de influir en su planeación oficial.

Algunos lugares de este espacio son reconocidos como centros culturales o puntos de encuentro de los grupos. Estos transitan, se desplazan o se quedan, se expresan y dejan marcas a su paso, generando así una injerencia en futuros planes oficiales de infraestructura que les pertenecen al haber sido logrados a través de sus manifestaciones, apropiaciones y peticiones.
Al generar cambios, estas últimas representan una influencia en la configuración informal del espacio público y llevan a otorgarle un sentido distinto al original, pues además del físico emerge uno político, dispuesto así por las prácticas sociales.

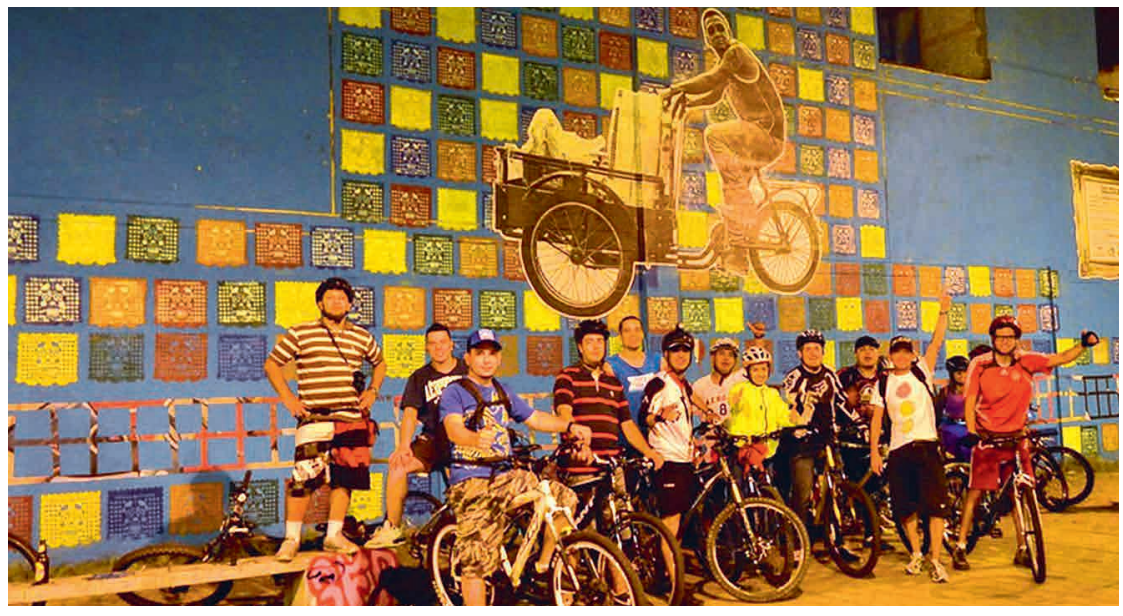

Figura 3. Intervenciones artísticas de los colectivos en el espacio público. Mayo de 2015 Fuente: https://www.flickr.com/photos/siclas/

\section{Respecto al engalle}

En este punto entran las simbologías implementadas por cada colectivo para hacerse notar, sus formas características de moverse, pensar y actuar, sus actitudes frente a la ciudad y cuanto ella tiene para ofrecerles. En muchos grupos, de vehículo funcional de transporte habitual, la bicicleta pasa a ser un símbolo, un instrumento de manifestación pacífica, la bandera de un movimiento cuya fuerza se incrementa y un bien para apoyar procesos culturales en que el elemento material adquiere diferentes connotaciones según sean sus usuarios y las necesidades de aquellos a quienes se ve ligado durante su ciclo de vida útil. Por su versatilidad, este objeto refleja su uso y otros propósitos, al funcionar bajo distintas dimensiones (transporte, mensaje, estandarte social, político y pacífico). Es el marco perfecto para expresiones gráficas y lingüísticas comunicativas del sentido de un individuo o de grupos organizados, al cargarse con el lenguaje estético de una comunidad creadora de códigos y significados orientados a comunicar sus intenciones. 

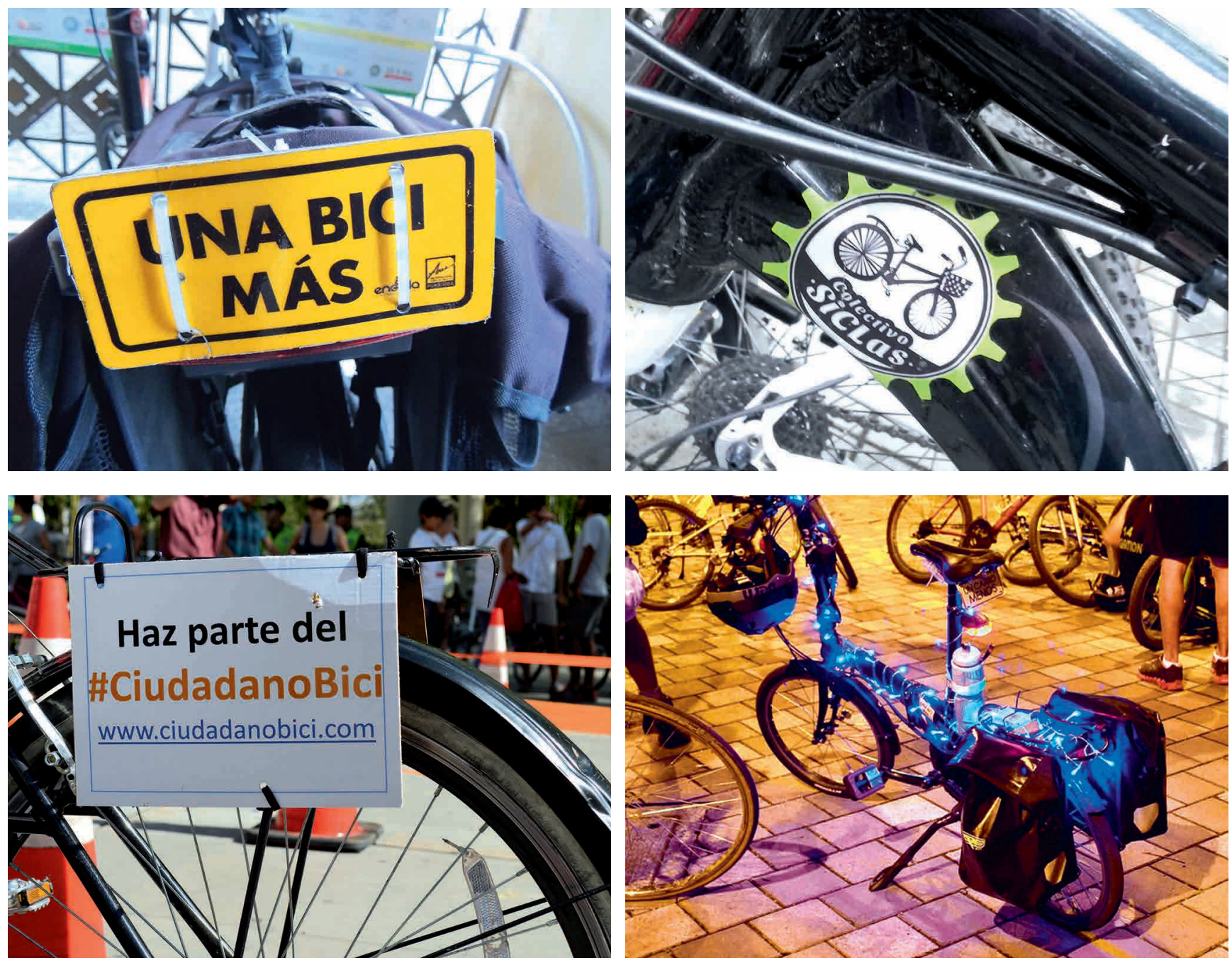

Figura 4. Placa "Una bici más", uno de los símbolos más representativos de los colectivos Figura 5. Calcomanía de "Siclas", símbolo gráfico común en las bicicletas de los participantes de este colectivo Figura 6. Letrero adaptado a la parrilla trasera de la bicicleta de un integrante de los colectivos Fuente: investigadoras. Abril de 2015. 
Las intervenciones de carácter estético que se muestran en las imágenes 4 a 7 son las manifestaciones materiales y gráficas por medio de las cuales se traducen los imaginarios de los colectivos culturales. La placa "Una bici más", es un símbolo grupal y masivo, uno de los elementos que unen a los colectivos, pues este no es de uso exclusivo de ningún grupo. La calcomanía de "Siclas" es un símbolo exclusivo de este grupo. Este tipo de letreros (\#CiudadanoBici) se usan para invitar a otros ciudadanos a ser parte del movimiento ciclista que recorre las calles de la ciudad. Estas materialidades conforman un lenguaje visual creado de manera progresiva por sus integrantes para generar así una familia de símbolos articuladora de un discurso colectivo.

\section{Respecto a la apropiación del espacio}

En ocasiones, la apropiación espacial por parte de los colectivos no es suficiente para transformarlo físicamente. Aun así, la repetición periódica de sus actividades ha dado vida a varios lugares: vías que se consideraban muertas para peatones y ciclistas, o de alto flujo vehicular como la Avenida Oriental, Palacé o la calle Colombia, por donde caminar o rodar es peligroso, son recorridas por estos grupos. En sus jornadas, enseñan a los ciudadanos que esos espacios también les pertenecen y no son de uso exclusivo de motos, carros y buses. A su vez, han implementado otros medios para hacerse escuchar respecto a este particular, desde documentos oficiales presentados a la Alcaldía hasta intervenciones artísticas públicas no oficiales y participación masiva en redes sociales y eventos.

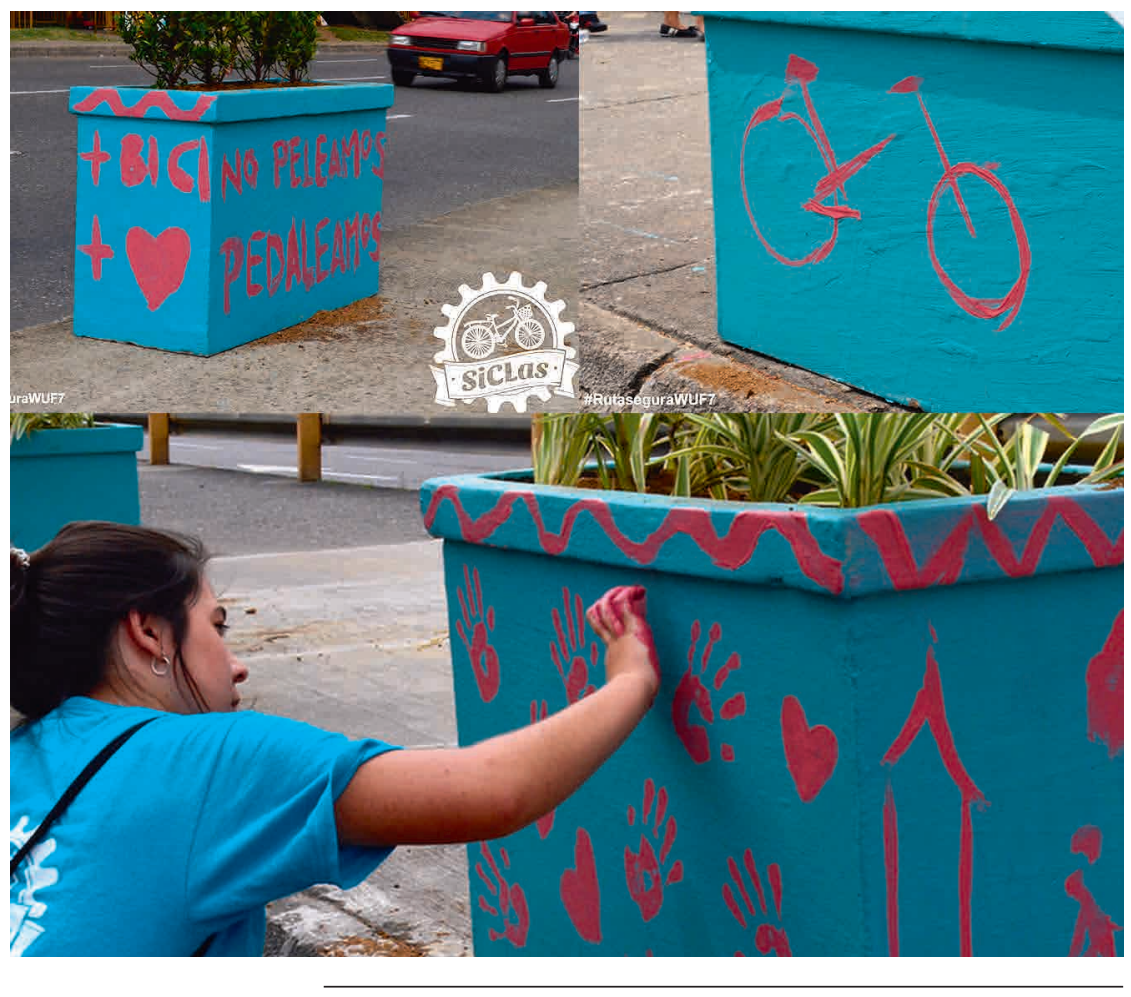

Figura 8. Mosaico que muestra la apropiación de la vía provisional para ciclistas de la Avenida San Juan, habilitada para el Foro mundial de la bicicleta. Mayo de 2015 Fuente: https://www.flickr.com/photos/siclas/ 
Respecto a la planeación urbana

La planeación urbana se ve influida por la acción de los colectivos, por su apropiación y uso del espacio público y por los engalles de sus bicicletas para comunicar sus propósitos. Miembros del colectivo Siclas se pusieron en la tarea de darle color a esta vía para los visitantes del Foro, además de manifestarse y exponer su petición para que esta vía fuera permanente y oficial dentro de la planeación pública de la ciudad. Ahora bien, cabe resaltar que la repercusión sobre este elemento oficial va más allá, pues todas estas prácticas dan pautas para planear la ciudad. Esto no se ve de inmediato, pero sí a lo largo del tiempo.

Parques del Rio es uno de los proyectos de transformación urbana más importantes en que han influido los ciclistas. Esta obra del área metropolitana busca incrementar el uso del espacio público, cambiar la cara de la ciudad y darle nueva vida a uno de sus mayores íconos, como es el río que la atraviesa de sur a norte. Otro ejemplo valioso es EnCicla, una respuesta del Metro y el área metropolitana a las peticiones de implementar vías seguras para ciclistas y conexiones con el sistema Metro. En esta iniciativa, entidades oficiales locales hicieron eco a las necesidades expresadas por los grupos y adecuaron puntos donde se instalaron cicloestaciones
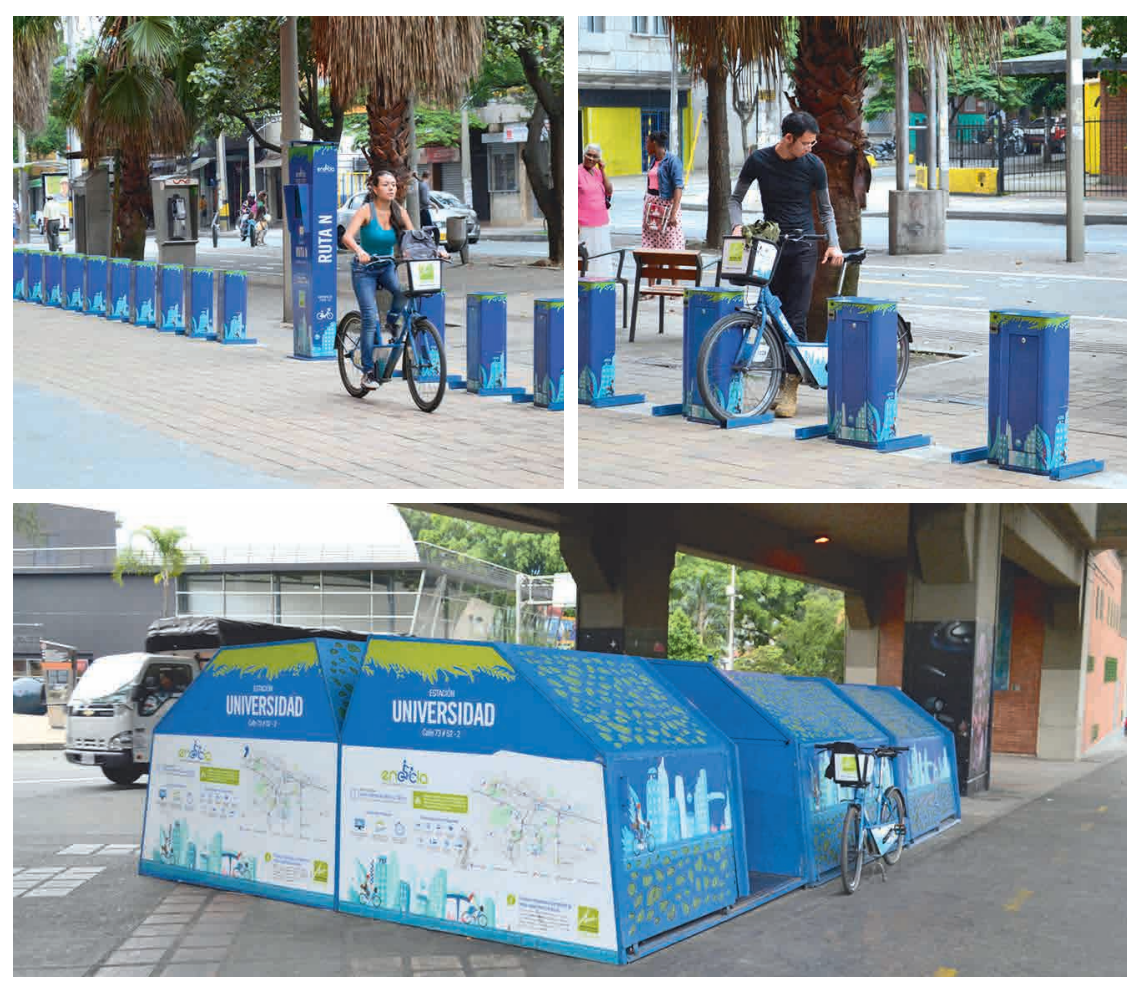

De lzquierda a derecha.

Figura 9. Joven transitando por las vías de EnCicla. Agosto de 2015 Fuente: http://www.sabaneta.gov.co/SalaPrensa/Publishinglmages/Miercoles_16_10_2013@@ENCICLA-600.jpg

Figura 10. Estaciones de EnCicla. Agosto de 2015 Fuente: http://www.mdeinteligente.co/estrategia/ciclorrutas-estaciones-en-cicla-yciclovias-de-medellin-y-su-area-metropolitana/

Figura 11. Estaciones de EnCicla. Agosto de 2015 Fuente: http://encicla.gov.co/noticias/encicla-sigue-creciendo 


\section{CONCLUSIONES}

Esta investigación, al enmarcarse en la línea de la cultura material, abordó temas socioespaciales y asuntos de la comunicación que terminan por conectar la ciudad, sus habitantes, sus objetos y el diseño, plasmado en distintas acciones. Puede decirse que en el caso estudiado la materialidad es una representación tangible de una información intangible asociada con cambios sociales.

Se contempló la forma como el diseño interviene en los hábitos del diario vivir y en los movimientos culturales. Está presente en cambios sociales relacionados con la bicicleta, ya sean gráficos, morfológicos o identitarios. Para los colectivos ciclistas, que al transformar hábitos y comportamientos influyen de cierta manera en toda la ciudad, el diseño ha sido importante al servir de medio, mensaje, canal y símbolo.

Al abordar el tema desde la cultura material se revelaron las relaciones entre los individuos, los objetos y los espacios, como también la manera en que los dos últimos adoptan un carácter simbólico por medio de prácticas y apropiaciones. Estas se expresan en materialidades y símbolos que llegan a convertirse en expresiones tangibles, marcan una forma de ver la ciudad y con el transcurrir del tiempo pueden reflejar un cambio resultante del pensamiento colectivo.

Ahora bien, desde la óptica del diseño el movimiento ciclista va más allá de lo material y puede ser asociado con otros fenómenos que permiten validarlo como una lectura de ciudad integrada por elementos tangibles e intangibles. Estos se han configurado a partir de la intervención simbólica de un objeto cuya fuerza se multiplicó cuando dejó de ser entendido como puramente funcional y recibió un sentido más político, visible y relevante. En efecto, las distintas formas de ver hoy en día la bicicleta poseen significados culturales, sociopolíticos y de estricto uso. 
En Medellín es considerada símbolo de movilidad sostenible, medio de manifestación pacífica, materialidad cargada de connotaciones políticas e ideológicas, instrumento para transmitir mensajes a través del engalle, expresión individual y colectiva, bandera de una forma de apropiación urbana, soporte para las peticiones que los colectivos buscan transmitir al Estado.

Respecto a lo último las manifestaciones continúan, pues a pesar de las transformaciones aún no se ha dado respuesta a todas las peticiones y expectativas de los colectivos. Por lo tanto, es un proceso vigente y en desarrollo que a su vez significa larga vida como objeto y canal de acción política para la bicicleta.

Medellín es una ciudad cambiante y dinámica, interesada en posibilitar condiciones de facilidad y seguridad para la movilidad de todos, ya sean conductores, ciclistas o peatones. Cada quien tiene deseos e imaginarios que se plasman de distintas formas: unos se apropian del espacio, otros se desentienden de él; unos lo transforman, otros solo lo transitan. Pero en general, los ideales apuntan hacia un entorno más vivible y tranquilo donde se tenga al menos un poco de lo anhelado. 
Carvajalino, H. (s.f.). Estética de lo popular: los engalles de la casa. Publicación de Barrio Taller. Serie ciudad y hábitat no11. Recuperado de: www.barriotaller.org

Castro, E. \& Rodríguez, P. (2005). Más allá del dilema de los métodos. Bogotá: Norma.

Constitución Política de Colombia (2015). Bogotá: Corte Constitucional.

REFERENCIAS

BIBLIOGRÁFICAS

Díaz, F. \& Ortiz, A. (2006). Ciudad e inmigración: uso y apropiación del espacio público en Barcelona. Barcelona: Universidad autónoma de Barcelona.

Diéguez, A. \& Guardiola, M. (1998). Reflexiones sobre el concepto de comunidad. De lo comunitario a lo local. Buenos Aires: Espacio.

Echebarría, C. \& Asuado, T. (2002). La planificación urbana sostenible. Bilbao: Universidad del País Vasco.

Ema, J. E. (2007). Lo político, la política y el acontecimiento. Foro interno. Anuario de Teoría Política, (7), 51-76.

García, M. d. L. (s.f.). Espacio público. Recuperado de http://www.ub.edu/multigen/donapla/espacio1.pdf

González, G. (1992). Planeación urbana. Planeación económico espacial. Revista de administración pública, (178), 99-108. 
Moranta, T. \& Urrútia, E. (2005). La apropiación del espacio: una propuesta teórica para comprender la vinculación entre las personas y los lugares. Barcelona: Universitat de Barcelona.

Morin, E. (1960). Teoría del Imaginario Colectivo. Recuperado de http://pendientedemigracion.ucm.es/info/per3/nueva_web_eva/material_para_descargar/ morin.pdf

Peralta, C. (2010). La Planificación Urbana. Recuperado de: http://urbanismounlar. blogspot.com.co/2010/07/la-planificacion-urbana.html

Recendiz, A. (2013). El lugar de la identidad. México.

Rojas, E. \& Guerrero, M. (1999). Engalle: más que un adorno, el lenguaje secreto de la minoría. Bogotá: Serie ciudad y hábitat no 6.

Sanín, J. (2009). Estéticas del consumo: configuraciones de la cultura material. Medellín: Universidad Pontificia Bolivariana. 